\title{
Características geológicas e petrográficas da Pedra da Gávea e Pedra Bonita, Rio de Janeiro
}

\author{
Thais Cristina Vargas Garrido
}

Universidade do Estado do Rio de Janeiro, Faculdade de Geologia, Departamento de Mineralogia e Petrologia Ígnea, Rua São Francisco Xavier 524 (Sala 4029/A), Maracanã 20550-013, Rio de Janeiro, Brasil. E-mail: thaisvargasuerj@gmail.com

Garrido T.C.V. (2021) Características geológicas e petrográficas da Pedra da Gávea e Pedra Bonita, Rio de Janeiro. Pesquisa e Ensino em Ciências Exatas e da Natureza, 5: e1690.

http://dx.doi.org/10.29215/pecen.v5i0.1690

Editor acadêmico: Silvio F. B. Lima. Recebido: 31 outubro 2020. Aceito: 08 abril 2021. Publicado: 14 abril 2021.

Resumo: Os saberes geológicos produzidos no meio acadêmico configuram um auxílio adicional à compreensão científica do ambiente natural. Este artigo objetiva apresentar as características litológicas e petrográficas dos afloramentos da Pedra da Gávea e Pedra Bonita no Rio de Janeiro. O método de trabalho consistiu da caracterização dos litotipos, descrição petrográfica, fotomicrografia e classificação das rochas. $\mathrm{O}$ granito é o corpo intrusivo de textura porfirítica na porção superior de ambas as pedras, tendo no topo a forma aplainada sub-horizontal (soleira) e a granulação muito grossa com megacristais de feldspato, enquanto o embasamento é constituído de biotita paragnaisse migmatítico, o ortognaisse bandado e o ortognaisse facoidal.

Palavras chave: Granito, gnaisse, litologia, petrografia.

\section{Geological and petrographic characteristics of Pedra da Gávea and Pedra Bonita, Rio de Janeiro}

Abstract: The geological knowledge produced in the academic environment is an additional aid to the scientific understanding of the natural environment. This article aims at presenting the lithological and petrographic characteristics of Pedra da Gávea and Pedra Bonita outcrops in Rio de Janeiro. The working method involved the characterization of the lithotypes, petrographic description, photomicrography and classification of the rocks. Granite is the intrusive body with a porphyritic texture in the upper portion of the two locations, both having a sub-horizontal planed shape (sill) at the top and very coarse granulation with feldspar megacrystals, while the basement consists of migmatitic biotite paragneiss, banded orthogneiss and facoidal orthogneiss.

Key words: Granite, gneiss, lithology, petrography.

\section{Introdução}

A cidade do Rio de Janeiro é repleta de cenários naturais de paisagens litorâneas e serranas com picos, montanhas e morros, onde sobressaem pontões com paredões de rochas metamórficas e ígneas que preservam características de um passado geológico altamente dinâmico. Três maciços, morfologicamente se destacam nesta paisagem: Tijuca, Pedra Branca e Gericinó-Mendanha. Esses maciços apresentam litologias diferentes e considerável relevância geológica e turística. Há tempos, são alvos do desenvolvimento de conceituados trabalhos (e.g. Paes Leme 1912; Lamego 1938, 1948; Helmbold et al. 1965; Pires et al. 1982; Penha \& Wiedemann 1984; Porto Junior 1993; Motoki et al. 2008). 
O presente artigo se refere às exposições rochosas Pedra da Gávea e Pedra Bonita, conhecidos pontos turísticos da zona Sul, região litorânea da cidade do Rio de Janeiro, situados na vertente oeste da Serra da Carioca no maciço da Tijuca. Abriga ali um patrimônio ambiental considerável com densa floresta, onde se destaca uma topografia com alinhamento WSW-ENE, fortemente acidentada com relevos íngremes e cristas abruptas. Tendo a sua maior altitude de $1.021 \mathrm{~m}$ (Pico da Tijuca), trata-se de um cenário muito típico que distingue fortemente a paisagem da região metropolitana do Rio de Janeiro.

Gávea é um nome antigo atribuído por alusão à plataforma de observação existente no alto dos mastros de embarcações da época das grandes navegações. $\mathrm{O}$ Rio de Janeiro era o destino de muitas dessas, que transportavam pessoas e mercadorias entre os portos do Oceano Atlântico (Bicalho 2003; Cavalcanti 2004) e Pedra Bonita, referindo-se à deslumbrante vista da paisagem obtida do local (Lamego 1964). A $1.3 \mathrm{~km}$ ao norte da Pedra da Gávea em continuidade geológica se encontra a Pedra Bonita (conhecida por ser um local para prática do esporte de voo livre).

Um único corpo de granito representa a porção superior de ambas às pedras. $\mathrm{O}$ embasamento se constitui de litotipos de gnaisse, dentre eles, o gnaisse facoidal, a rocha mais expressiva do relevo da cidade, tais rochas são paragnaisses e ortognaisses originadas do metamorfismo e deformação de rochas preexistentes sedimentares e ígneas (Lamego 1938; Helmbold et al. 1965; Penha \& Wiedemann 1984).

O objetivo deste artigo é apresentar os aspectos geológicos e petrográficos dessas pedras. Para tanto, são caracterizadas estruturas, texturas, fotomicrografias e morfologia dos litotipos, oferecendo assim, um material adicional à compreensão geológica.

\section{Material e Métodos}

\section{Revisão da literatura, trabalho de campo e de laboratório}

Inicialmente, os trabalhos sobre a geologia da região foram examinados com revisão da literatura em consultas seguidas de compilação de textos físicos publicados e pesquisas em mídia eletrônica. Posteriormente, a partir de trabalhos de campo e de laboratório, iniciou-se o estudo petrográfico macroscópico e microscópico salientado no presente trabalho. Portanto, os trajetos turísticos existentes foram percorridos e, usadas técnicas convencionais que incluem: localização geográfica, amostragem das rochas, observação com lupa de bolso com aumento de 10x, descrição e fotografias dos afloramentos e paisagens, junto com descrições das características macroscópicas e mesoscópicas como: tamanho, forma dos corpos, cor das rochas, identificação de feições específicas, estruturas, granulação e demais aspectos como presença de magnetismo, alteração e peculiaridades minerais. Assim, desde o início da caminhada nas trilhas e no percurso de subida pode se observar o gnaisse da base de cada montanha e na continuidade do caminho. Quatro amostras de blocos de aproximadamente $10 \mathrm{~cm}$ foram coletadas, naturalmente desprendidos dos afloramentos adjacentes. A área integra o Parque Nacional da Tijuca (PARNA Tijuca, criado em 1961), uma unidade de conservação brasileira de proteção integral da natureza administrada pelo Instituto Chico Mendes de Conservação da Biodiversidade (ICMBio, criado em 2007). A autorização de pesquisa na área (registro 71287-1) foi obtida conforme as determinações previstas na Lei $\mathrm{n}^{\circ}$ 9.985/2000 que pressupõe a coleta controlada de material e atividades de pesquisa científica. $\mathrm{O}$ estudo petrográfico das amostras e das respectivas lâminas delgadas foi realizado no Laboratório de Petrografia da Faculdade de Geologia (LPETRO) da Universidade do Estado do Rio de Janeiro (UERJ). Ele consistiu da descrição macroscópica e microscópica com análises das secções delgadas das rochas de 33 x $24 \mathrm{~mm}$ de dimensões. A mineralogia analisou as características sob microscópio petrográfico de luz transmitida, modelo triocular AxioScope 40, A150, Carl Zeiss e utilizou o software AxioVision 4.5.0 para a microscopia e fotomicrografias através da câmera modelo Axiocam ERc 5s, com aquisição de imagens e salvamento nos formatos ZVI e JPG. Por fim, as fotomicrografias de seções delgadas das amostras foram realizadas. 


\section{Localização e caracterização geológica da área de estudo}

A Pedra da Gávea (845 m de altitude) e a Pedra Bonita (696 m de altitude) situam-se em área metropolitana no sul da Serra da Carioca, respectivamente, nas coordenadas 22 59'17" S, $43^{\circ} 17^{\prime} 08^{\prime \prime} \mathrm{O}$ e $22^{\circ} 59^{\prime} 32^{\prime \prime} \mathrm{S}, 43^{\circ} 16^{\prime} 58^{\prime \prime} \mathrm{O}$. A região é adjacente à Baía de Guanabara entre os bairros de São Conrado, Itanhangá e Barra da Tijuca (Figura 1) e inserida no PARNA Tijuca. Essas pedras podem ser visitadas a partir de trilhas naturais para pedestres, no caso da Pedra Bonita pode ser também, por meio de veículos. Nesses caminhos tem-se contato direto com os afloramentos e a natureza preservada. A partir do bairro Itanhangá, seguindo por uma trilha de 1.600 m pela Estrada do Joá, é possível acessar a Pedra da Gávea da base ao cume. Embora, seja uma curta distância, são três horas de subida sem instrumentos de escalada em um trajeto bastante íngreme, onde é comum a existência de vários obstáculos da natureza com vegetação, raízes grossas, solo e blocos de rochas. Para a Pedra Bonita, a partir do bairro de São Conrado, prosseguindo de carro pela Estrada das Canoas, leva-se 20 minutos até um estacionamento do Parque Nacional da Tijuca e, segue-se a pé por um trecho de 1.500 metros, com subida até a rampa de prática do esporte de voo livre localizada no topo da Pedra Bonita.

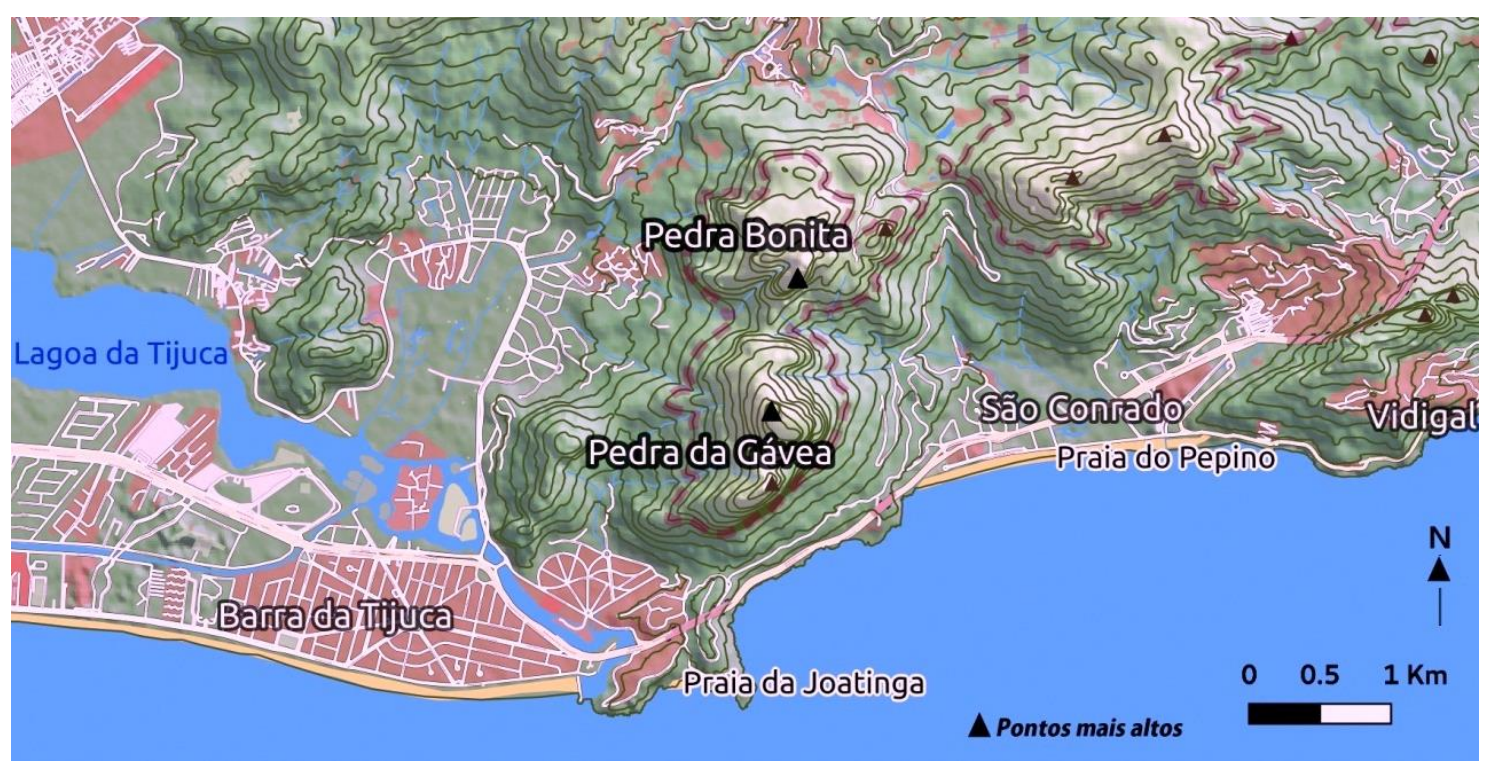

Figura 1. Localização da Pedra da Gávea e Pedra Bonita entre os bairros de São Conrado e Barra da Tijuca.

A morfologia local mostra as formas esculpidas pela denudação nas duas expressivas elevações em grandes paredões rochosos, nos topos sobressaindo superfícies aplainadas (Figura 2A-C). Tal relevo se associa à planície sedimentar (Figura 2D), com aporte de materiais minerais carreados desse entorno topográfico formando depósitos recentes (Asmus \& Ferrari 1978; Coelho Neto 1992), além da contribuição marinha (Amador 1992). O granito forma um corpo sub-horizontal (soleira) em ambas as pedras. Este é observado a partir de $750 \mathrm{~m}$ de altitude, e a espessura é de $100 \mathrm{~m}$, enquanto, na Pedra Bonita pode ser visto a partir de $650 \mathrm{~m}$, e a espessura varia de 20 a $40 \mathrm{~m}$. O gnaisse é a porção inferior de cada montanha e se encontra associado a um espesso manto de intemperismo. Entre as duas pedras é possível observar a topografia encurvada exibindo um contorno aproximadamente em V (Figura 2A). Penha \& Wiedemann (1984) atribuíram que tal configuração seja consequência do deslocamento vertical da falha geológica que aí ocorre. Na Pedra da Gávea, uma parede lateral vertical do lado oposto ao mar, assemelhase à face de uma pessoa (conforme mostrada na Figura 2B), devido ao intemperismo diferencial. Nessa parte podem ser observadas estruturas escavadas na superfície do granito, com formas aproximadas de elipse, que são enclaves. 


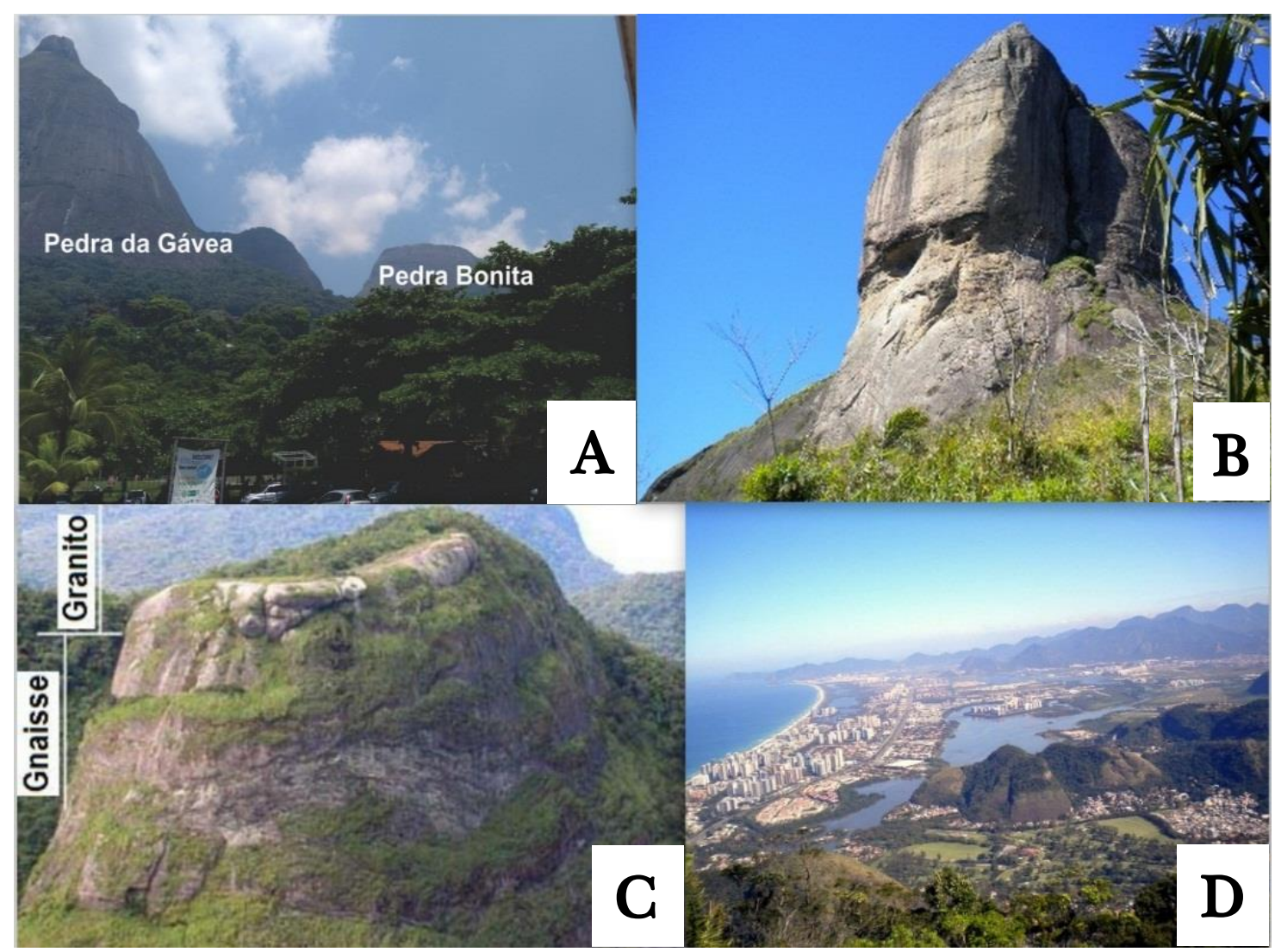

Figura 2. Pedra da Gávea, Pedra Bonita e a paisagem avistada da parte superior do relevo da área: A. A Pedra da Gávea na continuidade do seu traçado topográfico salienta um relevo mais baixo. $\mathrm{O}$ segmento morfológico posterior exibe uma superfície erodida, mais rebaixada ainda, de configuração em V com a Pedra Bonita; B. Porção da Pedra da Gávea conhecida como "Cabeça do Imperador", é um paredão nordeste a $845 \mathrm{~m}$ de altitude, com buracos semelhantes a olhos e feições (enclaves) concentradas de minerais ferruginosos, como a biotita escavadas por ação do intemperismo nessas porções; C. Forma aplainada subhorizontalizada do granito intrudido no gnaisse na Pedra Bonita ( $50 \mathrm{~m}$ espessura); D. Paisagem observada da Pedra da Gávea com vistas da Lagoa da Tijuca e a Praia da Barra da Tijuca.

Nesse cenário, de forma contundente, destaca-se ainda a vegetação abundante das encostas contribuindo para uma notável imagem no panorama geográfico da cidade. A vegetação é secundária e resultante do reflorestamento ocorrido na época do Segundo Reinado (1861) por determinação de D. Pedro II. Naquela época, a área se encontrava sem a proteção da vegetação nativa, devido ao desmatamento por necessidade de implantação das lavouras cafeeiras, de cana de açúcar e outras culturas nas fazendas locais (Menezes 2010). Dessa forma, os mananciais começaram a secar, o que prejudicou o abastecimento de água potável na cidade, então, capital do império. A saída foi reflorestar o maciço da Tijuca e demais áreas adjacentes (Vieira 2010). Contudo, o plantio de mudas ajudou no enriquecimento da vegetação auxiliando na formação da floresta, que conseguiu se regenerar, transformando-se em um belo parque para uso público até o presente.

Em campo, observa-se facilmente que a espessura do manto de intemperismo é maior, quando associado ao gnaisse. O trabalho de Motoki \& Vargas (2001) demonstrou que as rochas graníticas têm resistência ao intemperismo e a erosão no ambiente tropical em comparação com os gnaisses no maciço da Tijuca. Sendo diferente das rochas gnáissicas, as rochas graníticas apresentam textura homogênea não possuindo a orientação dos minerais, feição que age como veículo condutor de fluídos na superfície e interior do corpo rochoso como, por exemplo, a presença de água que frequentemente provoca alteração intempérica.

Todo o embasamento cristalino do sudeste do Brasil, do qual essas rochas fazem parte, representam um importante cinturão orogênico (orogenia Brasiliana) do Proterozóico- 
Cambriano (950-570 Ma) que se estende por $1.400 \mathrm{~km}$ ao longo do litoral, denominado Faixa Ribeira (Almeida et al. 1973). Tal feição é resultante da colisão de placas litosféricas, o que levou a formação do supercontinente Gondwana (nome em referência à região da tribo dos Gonds na Índia) há 570 milhões de anos. Sua história geológica inclui a formação de regiões estabilizadas sem deformação, os crátons, cercados de áreas orogenéticas estruturadas pela convergência compressiva (Figura 3). Os erógenos representam a porção deformada e são posicionados no entorno dos crátons.

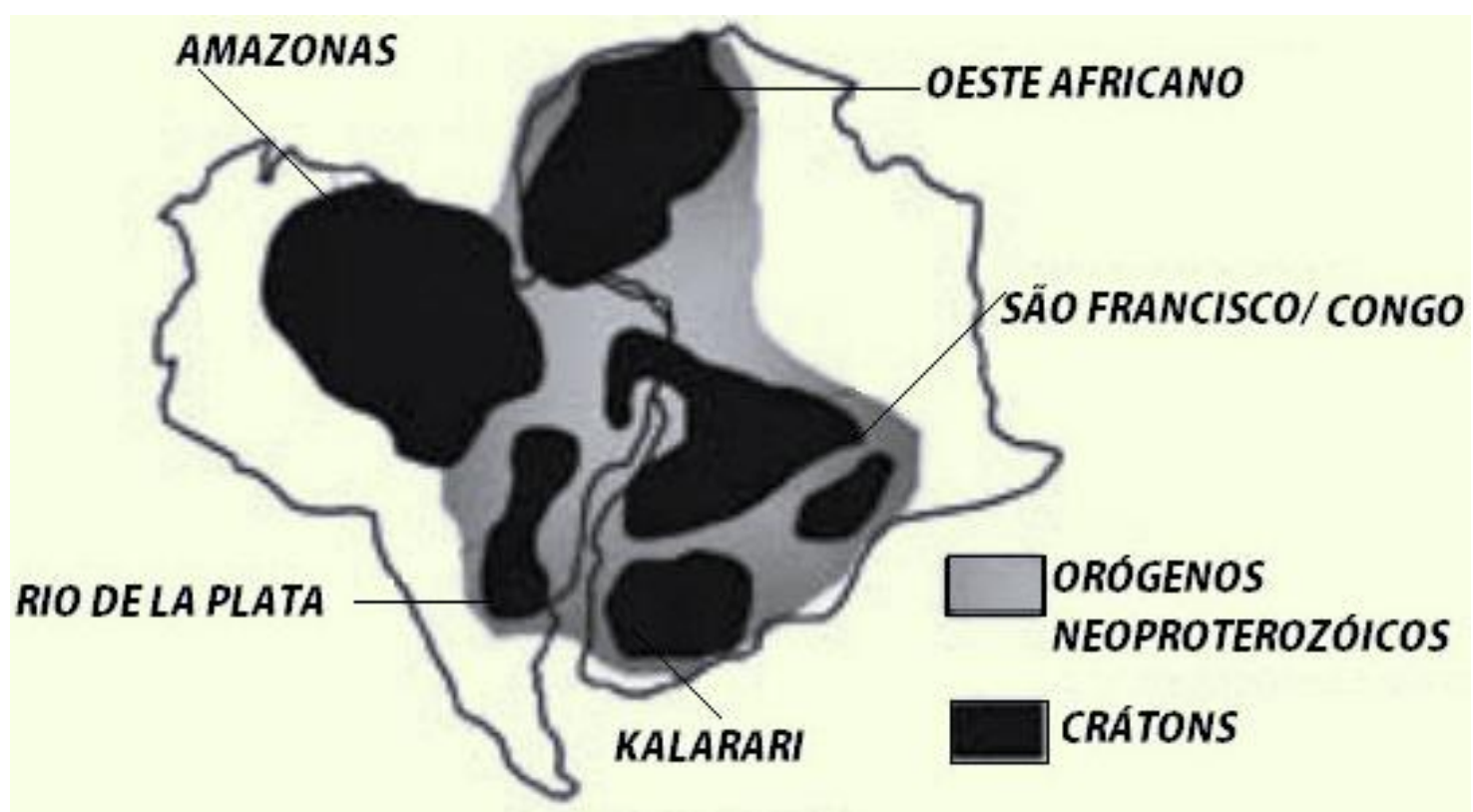

Figura 3. Esboço regional com os maiores crátons da América do Sul e África envolvidos na reconstrução esquemática do Gondwana ocidental e sua relação com as zonas orogenéticas conforme Alkmim \& Martins-Neto (2001).

Desse episódio fenomenal de grande porte e elevadas taxas de temperatura e pressão, deformação de terrenos, soterramento parcial e intrusão de magmas, resultou a formação da cordilheira Serra do Mar gerando os gnaisses e granitos dessa região. Tais rochas foram formadas em profundidades aproximadas de $20 \mathrm{~km}$ na crosta continental e surgiram na superfície a partir da erosão das camadas superficiais. No Mesozóico, o Gondwana se dividiu em outros continentes menores. Um desses, a América do Sul, separou-se do que é o atual território africano e deslocou-se exibindo desde então os imponentes relevos da Serra do Mar, como o maciço da Tijuca (Valeriano 2006).

Até o presente, não constam datações para as idades das rochas da Pedra da Gávea e Pedra Bonita. Entretanto, Silva et al. (2003) apresentaram idades para os gnaisses facoidais em que obtiveram $559 \pm 4$ Ma para o Pão de Açúcar e $560 \pm 7$ Ma para o morro do Corcovado. Foi também apresentada idade $513 \pm 5$ Ma para o granito Pedra Branca da fácies porfirítica Suite Suruí (Heilbron \& Machado 2003), essas se referem áreas próximas à estudada neste trabalho.

Inicialmente, a geologia do Rio de Janeiro foi mencionada por europeus participantes de missões científicas à América do Sul, a partir de descrições da paisagem com granitos e gnaisses (Caldcleugh 1825). Backheuser (1925) apresentou o primeiro mapa da geologia referente à área do antigo Distrito Federal, o Rio de Janeiro. Entretanto, outros notáveis trabalhos foram realizados sobre a geologia da cidade, dentre eles Lamego $(1938,1948)$ apresentou a teoria do protognaisse que teria dado origem aos diversos tipos existentes e desenvolveu um estudo geológico detalhado incluindo o mapa em escala 1:100.000. Paes Leme (1930, 1943) fez referências aos gnaisses porfiróides e apresentou a formação geológica do antigo Distrito Federal e Rosier $(1957,1965)$ interpretou o corpo granítico como uma intrusão pós-tectônica e abordagem no contexto da Serra do Mar. Helmbold et al. (1965) apresentaram o mais completo 
conjunto de dados e o mapeamento geológico em escala 1:50.000, o gnaisse facoidal ficou estabelecido como sendo constituinte da Série Superior, e Pires et. al. (1982) estudaram a granitogênese e definiram a estratigrafia para os litotipos.

Os litotipos do maciço da Tijuca, principalmente o gnaisse facoidal e também o granito tiveram grande importância quanto à aplicabilidade na construção civil, durante o processo do desenvolvimento urbano do Rio de Janeiro, o que se pode constatar em uma simples caminhada pelo centro da cidade. Dessa forma, ao longo da história, essas rochas foram utilizadas como matéria prima nas construções, em pavimentação e fachadas, o que influenciou intensamente $o$ caráter arquitetônico das edificações por suas características apropriadas, como sendo materiais resistentes e duráveis, tendo aspectos individualizados e exibindo diferentes tonalidades de cores e arranjos dos minerais, além do mais, conferindo especificidades nas estruturas e texturas (Mansur et al. 2008; Almeida \& Porto Junior 2012). Assim, na alvenaria e cantaria, as pedras naturais justapostas e superpostas foram aplicadas em estruturas unidas por argamassa e, como rocha bruta talhada (Cavalcanti 1950).

\section{Resultados e Discussão}

\section{Características da Pedra da Gávea e Pedra Bonita}

O embasamento do corpo granítico na área é representado por rochas metamórficas, litotipos variados de gnaisse: paragnaisse tais como biotita gnaisse de estrutura migmatítica, ortognaisse não porfiroblástico e ortognaisse porfiroblástico facoidal (Motoki 1991). O gnaisse facoidal foi o mais observado na área, sendo também a rocha mais comum nos afloramentos do Maciço da Tijuca.

Na altitude de $750 \mathrm{~m}$, o granito da Pedra da Gávea faz contato com o embasamento de gnaisse facoidal, em seguida, e em direção à base foi observado que o gnaisse é bandado e de contato leve transicional com o biotita gnaisse migmatítico.

O gnaisse migmatítico é uma rocha de alto grau metamórfico que revela uma mistura de estrutura gnáissica (orientada) e granítica. Na porção mais inferior da base das pedras ocorre o biotita gnaisse migmatítico de estrutura venular com cerca de $20 \mathrm{~m}$ de espessura, havendo veios e diques de pegmatitos e aplitos de espessuras $<5 \mathrm{~cm}$ a $\sim 1 \mathrm{~m}$, como em exemplos ilustrativos de corpos félsicos (Figura 4A-B), respectivamente, de granulação muito grossa e fina. Considera-se que o migmatito se forma em áreas de orogênese colisional em condições de temperaturas extremas e com proximidade de magma, tal que, este sendo injetado na rocha metamórfica hospedeira, promove a fusão parcial e gera estruturas félsicas como as mencionadas (Sawyer 2008). Esses veios intrusivos possuem direções aleatórias e são de magmas claros, esbranquiçados, ricos em minerais sílicosos como o feldspato e quartzo e penetraram nas fraturas do gnaisse. Quando o magma rico em materiais voláteis passa por um arrefecimento lento, os cristais formados desenvolvem tamanhos de centimétrico a métrico, e a rocha resultante apresentará granulação desde grossa a muito grossa, conferindo a textura pegmatítica. O aplito é uma rocha intrusiva que ocorre em pequenos e estreitos corpos de composição simples com feldspato, quartzo e muscovita. Tal granulação é uniforme com entorno de $2 \mathrm{~mm}$ e os minerais tem formas anédricas, ou seja, não mostram faces planas da sua cristalização; a textura é granular fina e característica, denominada textura aplítica ou sacaróide (semelhante a cristais de açúcar).

A amostra da Figura 4C é o gnaisse coletado na trilha da Pedra Bonita. Trata-se de gnaisse de textura porfiroblástica facoidal ou augen gnaisse, do grego, phakoeidés = lenticular, do alemão, augen = olhos, denominação devido aos grandes cristais com forma elíptica ou similar a olhos e se destacam do restante da rocha (porfiroblásticos). O gnaisse facoidal é uma rocha muito expressiva em ocorrências no entorno da Baía da Guanabara.

As porções graníticas na Pedra da Gávea e Pedra Bonita constituem um corpo comum com planos de contatos sub-horizontais com o gnaisse encaixante. Na Pedra Bonita, o plano do contato tem suave inclinação em direção ao norte, posicionando-se subparalelamente à superfície superior do maciço (Motoki 1991). No granito coletado no topo da Pedra Bonita 
(Figura 4D) destaca-se a cor rosa e foliação leve conduzida pelo fluxo magmático; na Pedra da gávea, a porção com megacristais de feldspato sobressai do restante do corpo granítico. Aí a porção do granito abaixo do topo apresenta uma faixa de enclaves e xenólitos, as partes seguintes são de gnaisse facoidal, gnaisse bandado e gnaisse migmatítico. Os enclaves são volumes menores de magma em que minerais máficos, silicatos de ferro e magnésio, geralmente pretos, como as biotitas são envolvidos por um material hospedeiro distinto. Em termos de nomenclatura, outras estruturas distinguem-se dos enclaves, como os xenólitos e os schlierens. Esses são fragmentos de rochas antigas que caíram no magma e, posteriormente, ficaram envoltos pela rocha ígnea originada e mais nova. Conforme o magma avança para a superfície, ele força seu caminho por fendas e rachaduras e fragmentos da rocha encaixante são desprendidos e mergulhados nele. Os xenólitos observados são de paragnaisses (biotita gnaisses) inseridos na faixa do granito. Os schlierens são pequenos volumes segregados e alongados com mineral tipicamente máfico (biotitas) que cristalizou do mesmo magma envolto.

A composição mineralógica tanto dos gnaisses como do granito é similar e constituída de quartzo, feldspatos potássicos microclina e ortoclásio, plagioclásio, biotita, muscovita, zircão, magnetita, epidoto, clorita, caulim, sericita, carbonato e óxidos de ferro.

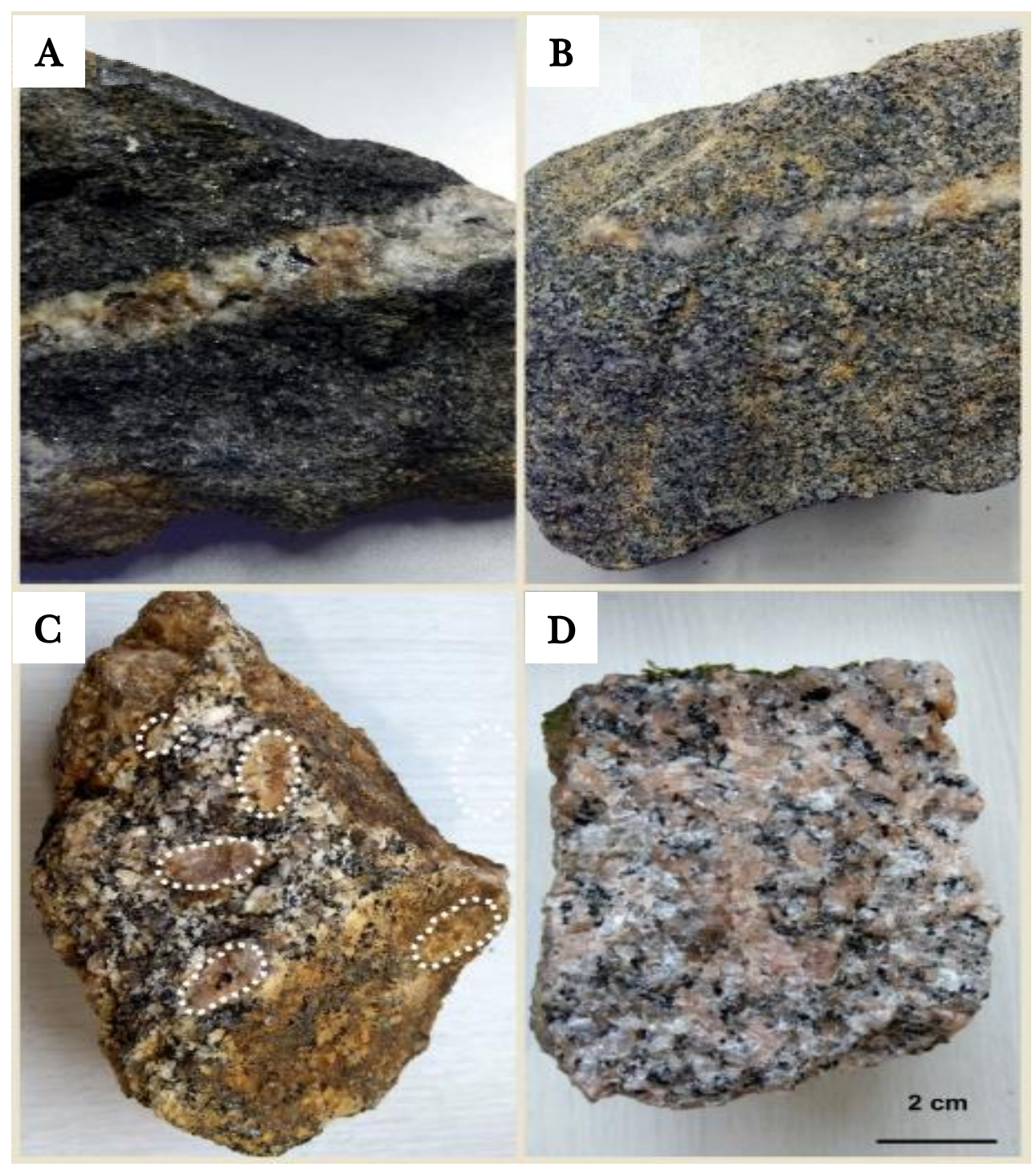

Figura 4. Amostras com intrusões félsicas (brancas) contendo quartzo, feldspato e biotita: A. Dique de pegmatito, com minerais centímétricos e textura pegmatítica; B. Veio de aplito, minerais milimétricos e textura equigranular sacaróide; C. Gnaisse porfiroblástico com partes claras constituidas por feldspatos e quartzo, caulim a argila branca e fina película alaranjada (óxido de ferro) ressaltando em branco as formas facoidal e semi-facoidal do feldspato alcalino; D. Granito porfirítico com feldspato alcalino retangular e semirretangular tendo uma leve estrutura de fluxo (alinhamento a direita superior da amostra). Escala das fotos: $2 \mathrm{~cm}$. 


\section{Caracterização macroscópica e microscópica do granito}

O granito nas duas pedras define características petrográficas fortemente similares. A Figura 4D exibe a fácies de textura porfirítica com fenocristais em matriz inequigranular e mostra a orientação dos feldspatos potássicos, revelando assim o movimento preservado do magma na sua solidificação. Macroscopicamente, o granito tem cor rosada, é leucocrático com $10 \%$ de minerais máficos (biotita) com granulação grossa, os grãos menores na matriz possuem de 2 a $5 \mathrm{~mm}$ de comprimento e cerca de $40 \%$ de fenocristais de feldspato alcalino microclina de 1 a $2.5 \mathrm{~cm}$ de comprimento mineral acessório magnetita $<1 \%$. Na porção superior e topo da Pedra da Gávea (Figura 5A-B), o afloramento ressalta curiosamente uma fácies muito mais grossa do que o restante do corpo abaixo. A textura é porfirítica e parte seriada (variação contínua do tamanho) com megafenocristais de feldspato alcalino de até $12 \mathrm{~cm}$ de comprimento, euédricos retangular e semirretangular, rosados e esbranquiçados devido à presença de caulim (argila formada da transformação química intempérica dos feldspatos). Nessa fácies corre esfoliação esferoidal superficial (Figura 5C), representa uma estrutura formada da alteração da rocha ocasionada pela ação do intemperismo mecânico e químico, em partes de maior fraqueza ao longo de linhas concêntricas chamadas isotermas, sendo uma feição semelhante a descascamento de cebola. Tal fenômeno é típico de rochas ígneas de estrutura maciça e granulação uniforme, como em parte se apresenta a matriz.

A Figura 5D mostra a rocha hospedeira migmatítica, sendo que os veios possuem espessuras que variam de 2 a $5 \mathrm{~cm}$. Os aplitos são mais estreitos com até $1 \mathrm{~cm}$ de espessura.

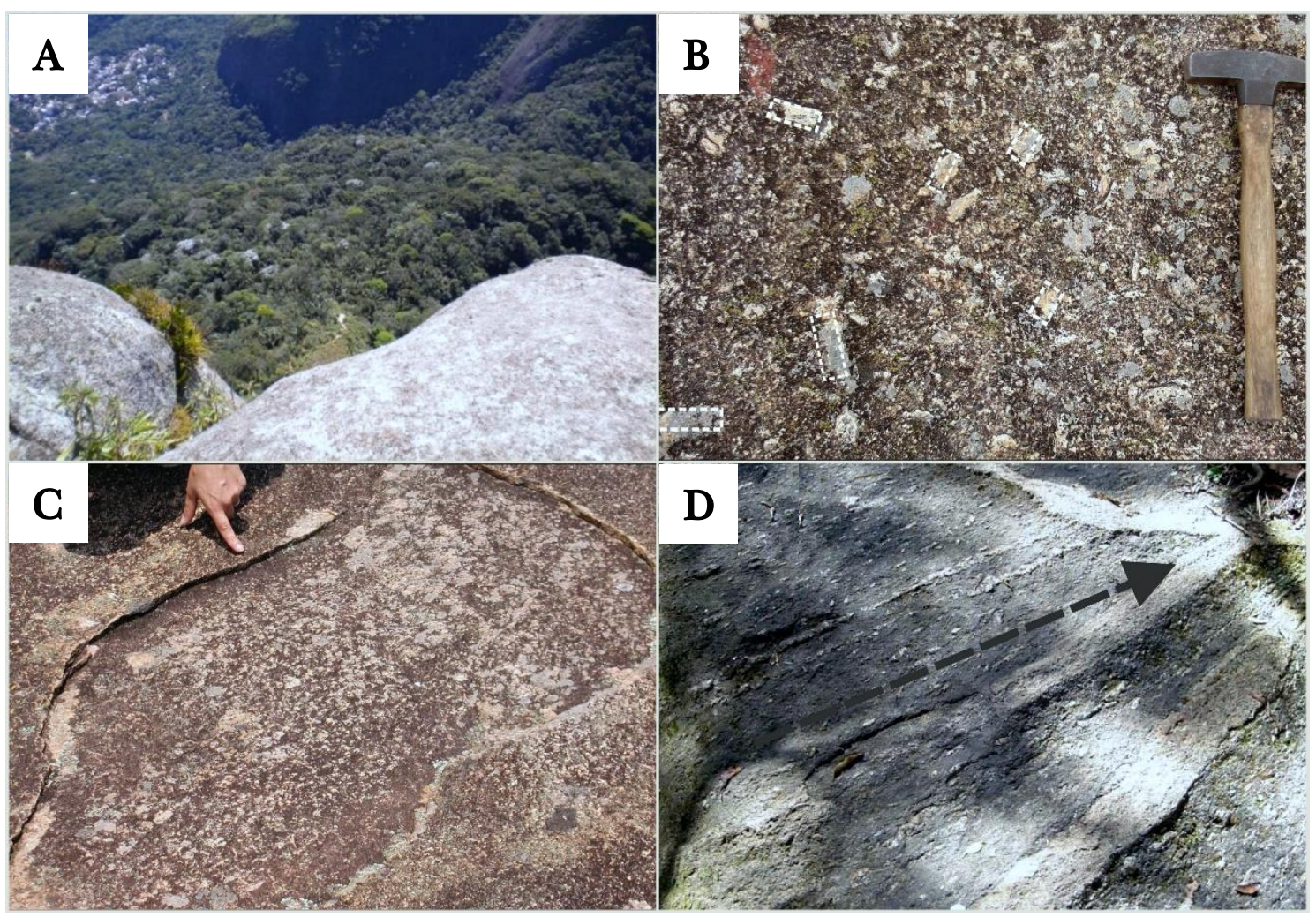

Figura 5. Caracterização do granito: A. Granito na Pedra da Gávea, a porção esbranquiçada é o caulim, argila da alteração química intempérica dos feldspatos e a densa floresta associada; B. Textura característica do granito do topo da Pedra da Gávea exibindo quartzo anédrico e concentração de feldspato alcalino como megafenocristais (cerca de $10 \mathrm{~cm}$ ), tabulares e semi tabulares curtos (retângulos ressaltados em tracejados), por vezes, zonados e com textura de fluxo; C. Superfície do granito com esfoliação esferoidal; D. Aspecto do biotita gnaisse migmatítico no embasamento com a seta indicando o direcionamento dos veios félsicos.

As análises microscópicas das lâminas de granitos (Figura 6A-B) permitiram reunir as seguintes características: textura porfirítica com fenocristais idiomórficos e subédricos de 
feldspato alcalino microclina pertítica com ex-solução de plagioclásio em manchas irregulares; os fenocristais não apresentam deformação plástica, sendo, portanto, típicos de granito porfirítico. A matriz é inequigranular constituída de feldspatos potássicos microclina e ortoclásio, quartzo, biotita cloritizada e muscovita. Os grãos de quartzo são anédricos, intergranulares ao feldspato com extinção ondulante e microfraturados (cerca de $30 \%$ ). A biotita ocorre em grãos anédricos com reentrâncias de reabsorção magmática e subédricos com hábito tabular de 0.2 a $2 \mathrm{~mm}$, ocorrendo também zircão e mineral opaco, como a magnetita (determinada macroscopicamente por sua propriedade magnética). A fase secundária é caracterizada pela presença de sericita, argila, clorita e carbonato. $\mathrm{O}$ granito é classificado pela proporção modal dos minerais félsicos, como sienogranito (o feldspato alcalino é predominante em relação ao plagioclásio de $\pm 10 \%$ ) (Streckeisen 1973).

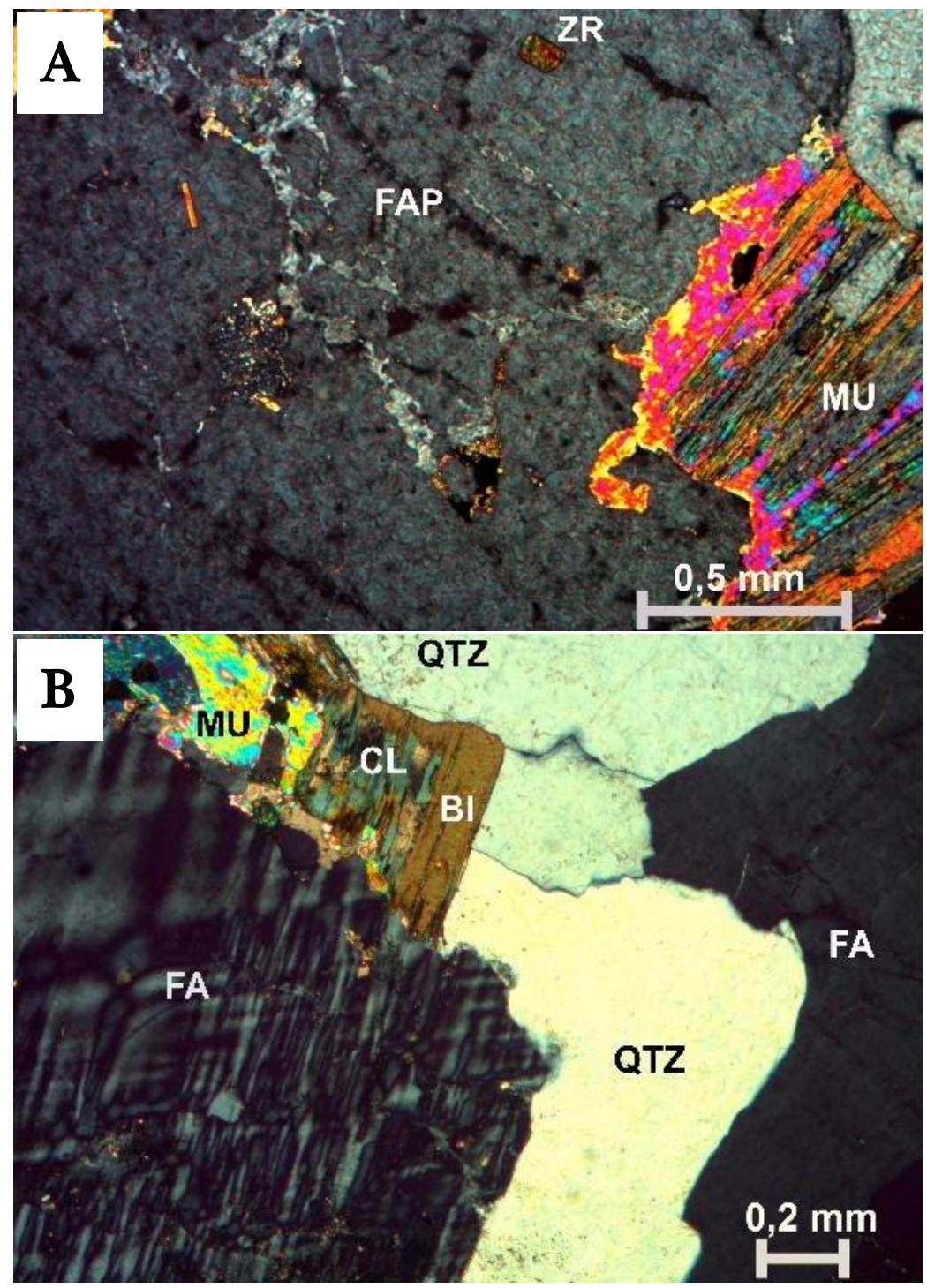

Figura 6. Fotomicrografias de secções delgadas do granito: A. Fenocristal de feldspato alcalino pertítico, muscovita e zircão com hábito prismático curto; B. Microclina com tartana e pertitas em manchas, grãos anédricos intersticiais de quartzo, biotita cloritizada e muscovita lamelar. Polarizadores cruzados (aumento de 25x): FA (Feldspato Alcalino-microclina e ortoclásio), FAP (Feldspato Alcalino pertítico), (QTZ) Quartzo, (ZR) Zircão, (BI) Biotita, (MU) Muscovita e (CL) Clorita.

\section{Caracterização macroscópica e microscópica do gnaisse}

O gnaisse migmatítico frequentemente exibe estrutura com dobras contorcidas, veios félsicos e segregações claras de composição granítica chamada leucossoma. Quando essas 
segregações possuem minerais máficos como hornblenda e biotita são denominadas de melanossoma. $\mathrm{O}$ bandamento gnáissico observado trata de uma feição metamórfica com faixas ou bandas alternadas, uma contendo biotita e opacos (máficos) e outra com quartzo e feldspato (félsicos).

Nos gnaisses porfiroblásticos destaca-se a textura com pórfiros de feldspato alcalino, por vezes, plagioclásio com cor esbranquiçada a cinza claro. A rocha de cor rosada possui a textura facoidal com facóides de microclina. As análises petrográficas revelaram os minerais essenciais: microclina, plagioclásio, quartzo e biotita, minerais acessórios (zircão, apatita magnetita e muscovita) e secundários (argila, clorita, sericita, carbonato, oxi-hidróxido de ferro respectivas cores avermelhada e amarelada e saussurita (produto de transformação do plagioclásio em argila, sericita e epidoto). A análise modal da rocha determinou a porcentagem média mineralógica: $44 \%$ feldspato potássico, $25 \%$ quartzo, $15 \%$ plagioclásio, $10 \%$ biotita, $\pm 6 \%$ magnetita e outros. Em seguida, são apresentadas as fotomicrografias (Figura 7A-B) dos gnaisses, respectivamente, da Pedra da Gávea e Pedra Bonita.

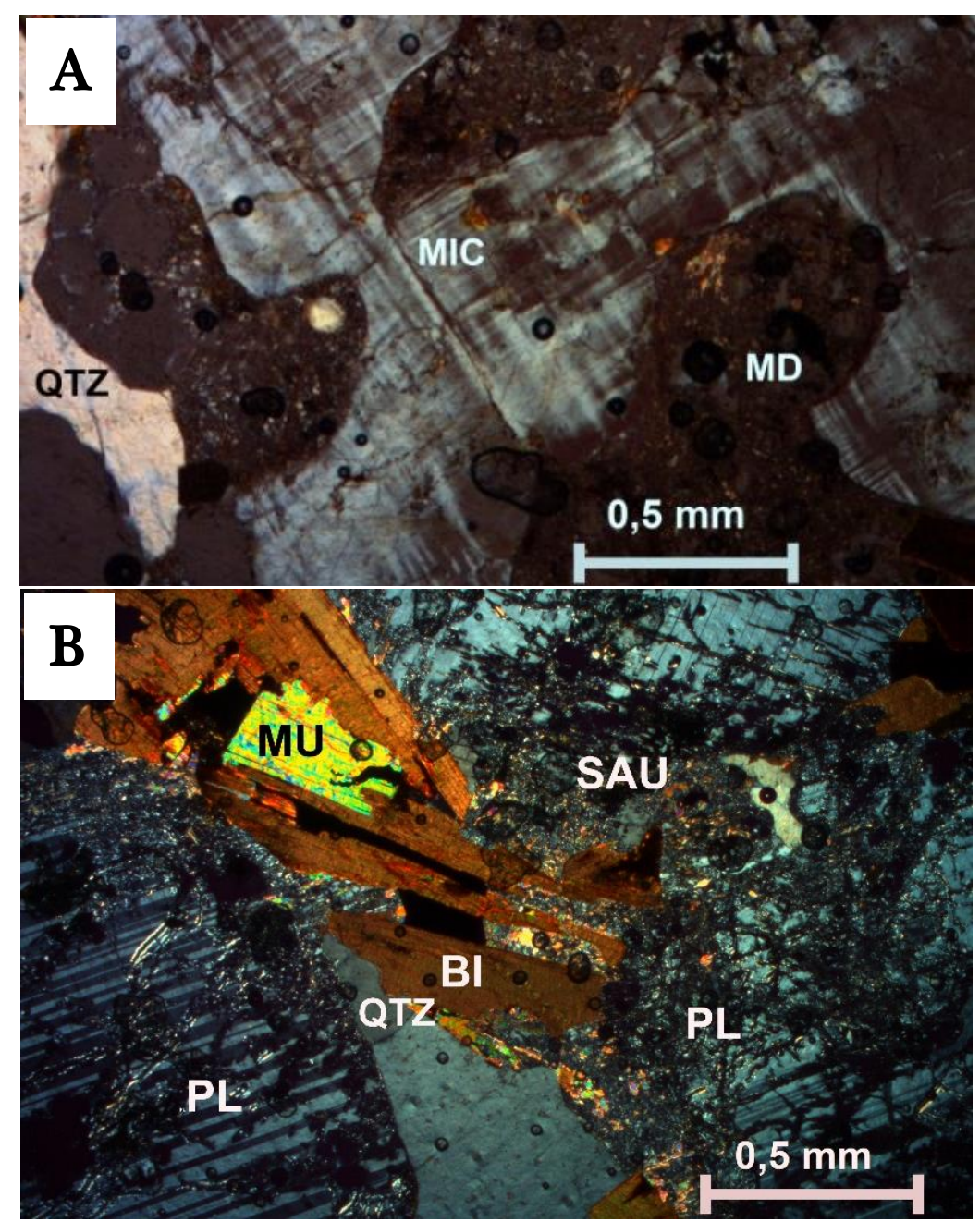

Figura 7. Fotomicrografias de secções delgadas dos gnaisses facoidais: A. Porfiroblasto de feldspato alcalino microclina, geminação xadrez (tartana) e aderências concentradas de material deutérico, consistindo de carbonato, sericita (mica potássica microlaminar) e argila e presença de óxi-hidróxido de ferro, quartzo anédrico intersticial de cor de interferência anômala, biotita cloritizada em lâminas submilimétricas com tons alaranjados (pequenas esferas escuras são bolhas de ar durante a confecção da lâmina delgada); B. Porfiroblastos de plagioclásio com geminação polissintética e ortoclásio, hidrotermalizados (com argila, sericita e saussurita), lamelas de biotita orientadas, quartzo intersticial e muscovita. Fotomicrografias com polarizadores cruzados (aumento de 25x). (MIC) Microclina; (MD) Material deutérico; (QTZ) Quartzo; (BI) Biotita; (MU) Muscovita; (PL) Plagioclásio; (SAU) Saussurita. 
A estrutura ígnea planar na porção superior de ambas as pedras apresenta características petrográficas muito similares, assim como, morfologia e relações de contato com $o$ embasamento, o que demonstra a existência de um único corpo de granito. Tal rocha, com uma leve foliação por fluxo magmático e, concentração de megacristais de feldspato delineia uma estruturação que evoca o assentamento mineral, o que representaria uma feição de câmara magmática remanescente. Acrescenta-se ainda, a esse cenário, a ocorrência de feldspatos com hábito cristalino retangular e sub-retangular, revelando um longo período da cristalização magmática.

A forma planar do corpo do granito, fácies homogênea de composição granítica, textura porfirítica, presença de megacristais, leve estrutura de fluxo, coloração rosada da rocha, incidência de xenólitos e enclaves, além de ortognaisses e migmatitos encaixantes representam também características do granito Pedra Branca (Penha 1984; Porto Junior \& Valente 1988; Porto Junior 1993). Pesquisas geológicas complementares, trabalhos regionais de campo e de geocronologia poderão investigar a possível relação existente entre esses granitos.

A presença de veios e diques félsicos de pegmatitos e aplitos relaciona-se ao ambiente de orogênese colisional, com rocha metamórfica na presença de magma em que se promove a geração de tais estruturas (Sawyer 2008).

\section{Considerações Finais}

O olhar científico sobre os granitos e gnaisses, rochas tão comuns no Brasil e no mundo, revela aqui as características litológicas e petrográficas dos lugares estudados, propiciando assim, um saber adicional ao conhecimento da geologia.

Os diferentes litotipos exibem feições e características do comportamento tectônico da área e vincula de forma contundente a geologia do passado ao geomodelado presente.

A atenção com o meio-ambiente é um tema frequente em todo o mundo. É importante e necessário o oferecimento de saberes científicos muitas vezes permanecidos no âmbito dos cientistas e especialistas, para uma percepção mais completa do ambiente natural, o que poderá contribuir para conscientização da valorização e conservação da natureza.

\section{Agradecimentos}

Agradeço, in memoriam, as participações nos trabalhos de campo dos professores Eurico Zimbres e Akihisa Motoki e à Ângelo Vimeney do Centro Excursionista Brasileiro pela contribuição cartográfica. Aos avaliadores pelas críticas construtivas ao manuscrito.

\section{Referências}

Alkmim F.F. \& Martins Neto M.A. (2001) A bacia intracratônica do São Francisco: Arcabouço estrutural e cenários evolutivos (p. 9-30). In: Pinto C.P. \& Martins Neto M.A. (Eds). Bacia do São Francisco: Geologia e Recursos Naturais. Belo Horizonte: Sociedade Brasileira de Geologia. 349 p.

Almeida S. \& Porto Junior R. (2012) Cantarias e pedreiras históricas do Rio de Janeiro: instrumentos potenciais de divulgação das Ciências Geológicas. Terrae Didatica, 8(1): 3-23.

Almeida F.F.M., Amaral G., Cordani U.G. \& Kawashita K. (1973) The Precambrian evolution of the South America cratonic margin south of the Amazon River (p. 411-446). In: Nairn A.E.M. $\&$ Stehli F.G. (Eds). The ocean basins and margins. Volume 1. New York: Plenum Publishing. $583 \mathrm{p}$.

Amador E.S. (1992) Baía de Guanabara: Um balanço histórico (p. 201-258). In: Abreu M.A. (Org.). Natureza e Sociedade no Rio de Janeiro. Volume 1. Rio de Janeiro: Secretaria Municipal de Cultura, Turismo e Esportes, Departamento Geral de Documentação e Informação Cultural, Divisão de Editoração. 352 p. 
Asmus H.E. \& Ferrari A.L. (1978) Hipótese sobre a causa do tectonismo cenozoico na Região Sudeste do Brasil (p. 75-88). In: Aspectos estruturais da margem continental leste e sudeste do Brasil. Volume 4. Série Projeto REMAC. Rio de Janeiro: Petrobrás-CENPES/DINTEP. 88 p.

Backheuser E.A. (1925) Breve notícia sobre a geologia do Distrito Federal, Brasil, D. F. Estatística da cidade. Anuário 1923/1924, 5(1): 19-31.

Bicalho M.F. (2003) A cidade e o império: O Rio de Janeiro no século XVIII. Rio de Janeiro: Civilização Brasileira. 492 p.

Caldcleugh A. (1825) Travels in South America, during the Years, 1819-20-21: Containing an Account of the Present State of Brazil, Buenos Ayres, and Chile. Volume 2. London: Ed. John, Murray. 406 p.

Cavalcanti A.M.S. (1950) Tecnologia da Pedra. Monografia (Curso de Engenharia), Escola Nacional de Engenharia, Universidade do Brasil, Rio de Janeiro.

Cavalcanti N. (2004) O Rio de Janeiro setecentista. A vida e a construção da cidade da invasão francesa até a chegada da Corte. Rio de Janeiro: Ed. Jorge Zahar. 443 p.

Coelho Neto A.L. (1992) O geoecossistema da floresta da Tijuca (p. 104-142). In: Abreu M.A. (Org.). Natureza e Sociedade no Rio de Janeiro. Volume 1. Rio de Janeiro: Secretaria Municipal de Cultura, Turismo e Esportes, Departamento Geral de Documentação e Informação Cultural, Divisão de Editoração. 352 p.

Heilbron M. \& Machado N. (2003) Timing of terrane accretion in the NeoproterozoicEopaleozoic Ribeira orogen (SE Brazil). Precambrian Research, 125(1-2): 87-112. https://doi.org/10.1016/S0301-9268(03)00082-2

Helmbold R., Valença J.G. \& Leonardos Junior O.H. (1965) Mapa Geológico do Estado da Guanabara, 1: 50.000. Rio de Janeiro. MME/DNPM.

Lamego A.R. (1938) Escarpas do Rio de Janeiro. Volume 93. Rio de Janeiro: DNPM/SGM. 71 p.

Lamego A.R. (1948) A Folha do Rio de Janeiro. Boletim n ${ }^{\circ}$ 126. Rio de Janeiro: DNPM/DGM. 30 p.

Lamego A.R. (1964) O homem e a Guanabara. Setores da Evolução Fluminense III. Publ. 5, Série A. $2^{\circ}$ edição. Rio de Janeiro: IBGE/CNG. 415 p.

Mansur K.L., Carvalho I.S., Delphim C.F.M \& Barroso E.V. (2008) Gnaisse Facoidal: A mais Carioca das Rochas. Anuário do Instituto de Geociências, 31: 9-22.

Menezes P.C.C. (2010) Natureza construída pelo homem (p. 31-33.). In: Menezes P.C.C., Vieira A.C.P. \& Issa B. (Eds). Parque Nacional da Tijuca: uma floresta na metrópole. Rio de Janeiro: Andrea Jakobsson Estúdio. 164 p.

Motoki A. (1991) Granito da Pedra da Gávea, sheet sub-horizontal ou base de plutão? (p. 155191). In: $2^{\circ}$ Simp. Geol. Sudeste. São Paulo: SBG/SP-RJ.

Motoki A. \& Vargas T. (2001) Geologic observation of natural and artificial recovery processes of brazilian tropical forest destroyed by debris flow and bauxite mining (p. 54-55). In: International Symposium on Application of Natural Materials for Environmental Geotechnology. Tokyo: Proceeding papers.

Motoki A., Giannis H.P., Sichel S.E., Cardoso C.E., Melo R.C., Soares R. \& Motoki K.F. (2008) Origem dos relevos do maciço sienítico do Mendanha, RJ, com base nas análises geomorfológicas e sua relação com a hipótese do vulcão de Nova Iguaçu. Geociências, 27(1): 97-113.

Paes Leme A.B. (1912) Gnaisses do Rio de Janeiro. Rio de Janeiro: Typ. Gonçalves. 38 p.

Paes Leme A.B. (1930) O Depoimento do Brasil na discussão da Theoria do Deslize dos Continentes segundo Wegener. Boletim do Museu Nacional, 5(4): 41-56.

Paes Leme A.B. (1943) História física da Terra vista por quem a estudou no Brasil. Rio de Janeiro: F. Briguiet \& Cia. 1020 p.

Penha H.M. (1984) Geologia do Maciço da Pedra Branca, Rio de Janeiro, RJ. Anais da Academia Brasileira de Ciências, 56(3): 1-355.

Penha H.M. \& Wiedemann M.C. (1984) Granitóides da região central do Rio de Janeiro (p. 54335455). In: Congresso Brasileiro de Geologia. Rio de Janeiro: SBG.

Pires F.R.M., Valença J.G. \& Ribeiro A. (1982) Multistage generation of granite in Rio de Janeiro, Brazil. Anais da Academia Brasileira de Ciências, 54(3): 563-574. 
Porto Junior R. (1993) Petrologia das rochas graníticas das serras da Pedra Branca e Misericórdia, Município do Rio de Janeiro, RJ, Brasil. Dissertação (Programa de Pós-Graduação em Geociências), Universidade Federal do Rio de Janeiro, Instituto de Geociências, Rio de Janeiro.

Porto Junior R. \& Valente S.C. (1988) As rochas granitoides do norte da Serra da Pedra Branca e suas relações com as encaixantes gnaíssicas na região de Bangu, Rio de Janeiro, RJ (p. 10661079). Congresso Brasileiro de Geologia. Belém: SBG.

Rosier G.F. (1957) A geologia da Serra do Mar, entre os picos de Maria Comprida e do Desengano (Estado do Rio de Janeiro). Boletim DGM/DNPM, 166: 1-58.

Rosier G.F. (1965) Pesquisas Geológicas na parte oriental do Estado do Rio de Janeiro e na parte vizinha do Estado de Minas Gerais, Brasil. Boletim DGM/ DNPM, 222: 1-41 p.

Sawyer E.W. (2008) Working with migmatites: nomenclature for the constituent parts (p. 1-28). In: Sawyer E.W \& Brown M. (Eds). Working with migmatites, Short Course Series. Quebec City, Canada: Mineral Association of Canada.

Silva L.C., Mcnaughton N.J., Hartmann L.A., Fletcher I.R. \& Silva H.C. (2003) Zircon U-Pb SHRIMP dating of the Serra dos Órgãos and Rio de Janeiro granitic suites: implications for the $560 \mathrm{Ma}$ ) Brasiliano/Pan-African collage. Revista Brasileira de Geociências, 33(2): 237-244. https://doi.org/10.25249/0375-7536.2003332237244

Streckeisen A. (1973) To each plutonic rock its proper name. Earth-Science Reviews, 12: 1-33. https://doi.org/10.1016/0012-8252(76)90052-0

Valeriano C. (2006) A Odisséia do Pão de Açúcar - As rochas contam sua história. Projeto Caminhos Geológicos. DRM-RJ. Disponível: http://www.drm.rj.gov.br (Acessado 12/02/2021).

Vieira A.C. (2010) A montanha encantadora (p. 13-30). In: Menezes P.C.C., Vieira A.C.P. \& Issa B. (Eds). Parque Nacional da Tijuca: uma floresta na metrópole. Rio de Janeiro: Andrea Jakobsson Estúdio. 164 p. 